\title{
CIVIC CONSCIOUSNESS OF STUDENTS IN HIGHER EDUCATION AS A WORLDVIEW PHENOMENON: CONTENT AND STRUCTURE
}

\author{
V. N. Pervushina ${ }^{1^{\star}}$, V. S. Ostapenko ${ }^{2}$, N.M.Morozova ${ }^{3}$, L. M. Savushkin ${ }^{4}$, I.M. \\ Bocharova $^{5}$ \\ ${ }^{1}$ State University of Justice, Central branch, Voronezh, Russian Federation, email \\ veravalen47@yandex.ru \\ ${ }^{2}$ State University of Justice, Central branch, Voronezh, Russian Federation, email ostapenko- \\ vl@yandex.ru \\ ${ }^{3}$ Voronezh, Voronezh Institute of the Ministry of internal Affairs, Voronezh, Russian Federation, \\ email nadezhdamorozova11@gmail.com \\ ${ }^{4}$ State University of Justice, Central branch, Voronezh, Russian Federation, email \\ savushkin.lieonid@mail.ru \\ ${ }^{5}$ State Technical University, Voronezh, Russian Federation, email irinabocharova58@gmail.ru \\ ${ }^{*}$ Corresponding Author
}

\begin{abstract}
The role and importance of civic consciousness as a worldview phenomenon of young people who are studying at universities is increasing under the conditions of an openness and availability of information about any sphere of state and individual life in the era of development of civil society. The attitude towards the formation of a citizen should be based on the ideas of patriotism, statehood, morality, and legality which, unfortunately, are being "blurred" and lose their relevance during periods of falling morals, permissiveness, and commercialism. It is no accident that the amendments to the Constitution of the Russian Federation introduce a ban on foreign citizenship or a foreign residence for the representatives of authorities. Civic consciousness is the framework, the foundation on which the worldview maturity of a young personality should be built. Therefore, the purpose of the paper is to identify the content and structure of the concept of civic consciousness on the basis of the worldview approach as the dominant one, allowing us to present this concept as a personal worldview phenomenon formed among students in the educational environment of the University. This statement is actualized in the paper. We take the position that it is impossible to form such a complex worldview phenomenon during education at the University, without understanding its content and structure, the main components, determining the ways of implementing such work in specific forms, means, and methods. We consider that the concept of "civic consciousness" should be regarded as a personal worldview phenomenon, combining cognitive, axiological, motivational, and activity components. Such an approach is not sufficiently analyzed at home literature. Analysis of the concept of "civic consciousness" is not fruitful in terms of properties and quality of a personality..
\end{abstract}

Keywords: civic consciousness, worldview phenomenon, content, structure, students, education, systemstructural approach, action-theoretical approach 


\section{INTRODUCTION}

Civic consciousness is the definition of great importance in many aspects. First, it identified with the problem of social development. Second, it is relevant to the development of civil society, openness and accessibility of information about any sphere of life of state and a person. So the role and importance of civic consciousness is increasing as a worldview phenomenon during the education of students at universities. Third, the definition of civic consciousness should be analyzed from a system and structural perspectives with special attention to the formation of value-normative attitude of students that affect on cultural and national identification. Education of civic consciousness should be based on the ideas of patriotism, statehood, morality, and legality. But modern civilization is characterized by instability, consumerism, commercialization (the power of money); it is defined by its being rooted in the crisis of spiritual values. Civic consciousness is the foundation on which the ideological maturity of a young person should be built. The authors offer a frame of reference for analyzing content and structure of civic consciousness as a personal worldview phenomenon, forming at students during education. The system-structural approach sketched in the paper is meant to determine the concept of civic consciousness. We use an action-theoretical approach as well. This approach is dealt with the study of social action-behavior in the Weberian sense, involving the intervention of thought processes - intentions, values, beliefs, and attitudes. Unity of these approaches can gain an image of human's as an active being, on the one hand. On the other, system approach focuses on the large-scale integration of society, on understanding of it as composed of institutions: economic institutions, family, education, army, and others, reflecting patterned behaviors and social structure (status/role relationships) that fulfill basic social needs. The main general cultural values express preferred behavior and attitudes about good, right, beauty, patriotism as well, for example. Patriotism is respect for and pride in the country. The general values, rooting in traditions, folkways, being taken-for-granted, are rules that people follow without thinking about them. It is the cultural code of the country. The destruction of the cultural code is the destruction of a human being and a country, loss of cultural identity and statehood. Patriotism is the basis for the existence of cultural identity.

\section{FORMING OF CIVIC CONSCIOUSNESS IN EDUCATIONAL PROCESS AT UNIVERSITIES}

The problem of forming of civic consciousness as a worldview phenomenon plays a key role in the development of the state. It is the unification of the efforts of all citizens and their high responsibility for the fate of the fatherland is manifested in civic consciousness. This problem is also relevant to modern Russia, where the education of civic consciousness is a priority goal of the state policy. For the first, it is necessary to work out an explanation of the definition of civic consciousness. For the second, special attention is paid to the forming of civic consciousness in educational process at universities. Why particular emphasis is placed upon universities? Universities are the major channel of cultural transmission, articulating the whole complex of values, attitudes, and behaviors that reflect the dominant values and views of the society which tie up moral, legal, and aesthetic norms with the adherence to the dominant culture's values shared by the majority of people. As we know socialization continues across the culture life course. Were it not for socialization, the renewal of culture could not occur from one generation to the next one. Of course, early socialization differs from later one in a number of ways. Primary socialization is directed towards elementary matters as training and language competence. Adult socialization, for example, at universities requires a synthesis of new elements - resisting ones and role transition. Adult socialization focuses on selfawareness of individuals' places in society, social interests in general. Universities are institutions of socialization where the development of civic consciousness is possible. At universities social interests are articulated and formulated. Activities of social concerns: helping others, promoting national understanding, participating in community action programs, and keeping up with political affairs can be formed at educational process. Teaching of social sciences and humanities (law, history, cultural and political studies, philosophy, sociology, etc.) affects on forming of civic consciousness. In due course students accept and redefine not only social roles, make adjustment in values, beliefs, and self- awareness, but aware of unity of individual and social interests, unity of a human being and a citizen. Well educated persons can show their civic consciousness through an active attitude and behaviors to events happening around them, the ability to analyze it independently; through interest to political processes. These actions will be carried out according to the individual's worldview values.

It is the presence of these values that contributes to the formation of a sense of honor and duty, being proud of the country, its culture and history; confidence in choosing the right goals and methods to achieve them; the ability to cherish the shrines of the country as personal ones. Values deal with fundamental and important parts of social life. Shared values, invested with deep emotional significance, are moved to 
participate in the fate of the people around you and the fate of the country as well. It is the teaching as a conscious activity of students, as a process, realizes in their perception of certain objects and processes, comprehension of the studied facts, phenomena, and ties between them, generalization of the perceived facts, consolidation and application of knowledge (M. A. Danilov 2005, 115).

Educational activity is a joint activity of a teacher and a student. The role of teacher is defined in terms of its relationship to the role of student. Thus, the subject of educational activity is a collective (social) subject a priori. The subjects participating in it are differed in age, individual characteristics, social status, and religious affiliation, but the common goal (in our case, the education of civic consciousness) unites them in a kind of coordinated system.

Learning is a phenomenon related to social reality. The modern social environment is constantly becoming more complex. An individual needs to master more complex skills and abilities to interact with it. This interaction involves not only the people but also the products of their activities, in particular scientific knowledge, "which serve as a means of further activities, the main function of which is to ensure the maintenance and continuous development of human society" (M. S. Kagan 1974, 48). Such an interaction through the development and "appropriation" of accumulated human experience (existing values, traditions), passed down from generation to generation, and forms a civic attitude. This experience is again transmitted in the process of teaching as a social activity. Consequently, education is a specific type of social activity, through which social experience is transmitted, and civic consciousness is being formed as a key characteristic of the relationship between a person and the state.

\section{DEFINING CIVIC CONSCIOUSNESS: CONTENT AND STRUCTURE}

There is no doubt that understanding of civic consciousness is marked by widespread disagreement over how the term civic consciousness should be analyzed. To our opinion, we cannot understand such a complicated phenomenon as civic consciousness is and its forming at students in universities without regarding genesis, content and structure of civic consciousness, its main component that determine the ways of its forming in the process of studying and working (forms, means, and methods) .

The classic formation of the former definition is offered by ancient philosophers Plato (Plato 2017, 513-530; 671-695), Aristotle (see Aristotle, Vol. 4. 1984), and others. They argued in favor of the term activity and unity of individual and social interests, individual and community, human being and citizen. The concept of activity is closely connected with the ethics of perfectionism. Through civic consciousness improving of an individual and society is aiming at.

At the Renaissance and Modern times the concept of civic consciousness was understood in terms of education. The main goal was to educate a person as a citizen, a patriot. It was important to form the civic qualities of an individual (Erasmus Roterdamus 1986,90-218; see M. de Montaigne 2019, Ch.. Fourier 1939, Henri de Saint-Simon 1948, Zh. - Zh. Rousseau 1981, etc.). This point of view on civic consciousness we can see in works of Russian teachers (e.g., A. S. Makarenko 1986; V. A. Sukhomlinsky 2011; K. D. Ushinsky 2004). They defined civic consciousness in terms of education as well, paying particular attention to the development of feeling of citizen and patriot of the country. On this way of distinguishing various conceptions of civic consciousness, foreign and Russian scholars are on the same side, understanding civic consciousness in terms of primarily civic-patriotically education.

The representatives of modern pedagogy view the phenomenon of civic consciousness in different ways. $L$. $P$. Bueva analyzes it at macro theoretical level having important significance for the study of pedagogical aspects of civic consciousness (see L. P. Bueva 1971\}. A. A. Aronov defines civic consciousness in narrow sense as patriotic education based on the people military and labor traditions (see A. A. Aronov 1989).

Foreign scientists J. Bradley (Bradley2009), G. Almond, S. Verba (G. Almond, S. Verba 1963), by contrast, focus on development of civic consciousness relevant to the development of civil society, human rights in Western countries, highlight the ways in which sociocultural forces enable individuals to carry out existing democratic and universal human values, tolerance, trust, and respect between people in civil society. This way of carving up the pedagogical literature of foreign scientists on civic consciousness is to point out those that define civic consciousness in terms of legal practice.

Some of the theorists analyze civic consciousness, pointing out its essence and content. They offer such a definition in which civic consciousness is understood as an active conscious attitude of a person in carrying out of socio-economic, political, and other obligations. The civil attitude is in this sense "a relatively stable semantic system of individual consciousness,- reflecting the socially determined attitude of a person to his/her country, civil society and himself/herself as a member of it" (O. I. Shatalovich, 2006, 109). They 
suggest that understanding of civic consciousness as integrative image of social development and the way of civic self-identification and motivation of social activity is important.

Others scientists define civic consciousness as an integrative quality of the individual in such aspects as worldview (knowledge, beliefs, and value orientations) and behavioral (norms, attitudes). According to this point of view, civic consciousness is an integral worldview personal quality that «characterizes the individual in terms of relationship to the social environment. This concept reflects the political and moral rights and obligations of citizens in relation to society, the expression of a person's civic attitude to society and others" (E. P. Belozertsev 2000, 349). On this way of distinguishing various conceptions of civic consciousness Shatalovich and Belozertsev are on the same side, since both of them understand civic consciousness as primarily a personal worldview phenomenon, and in action-theoretical terms. Such an approach does not reveal the full depth of this concept and diversity of its content and structure, so it is necessary to strengthen the worldview status, identify the main structural components that determine the phenomenon of civic consciousness relevant to students in higher education.

We consider that constitutive conception of civic consciousness is necessary. We focus on not only individual but trans-individual ways in which persons and social environment they inhabit are functioned and constituted. We view civic consciousness as a system and consider a system approach fruitful for studying civic consciousness and finding explanations for it. On this point of view, civic consciousness is a combination of parts that form a larger whole. So we combine action-theoretical approach (including worldview aspect, structuring possibilities for actions) and system one.

The mentioned above approaches can formulate the concept of civic consciousness containing structural parts, determining the phenomenon of civic consciousness, since the definition of civic consciousness as a personal worldview phenomenon of students combining cognitive, axiological, motivational, and activity components which are not being sufficiently studied in the scientific literature.

First, the cognitive component involves:

- Students ' assimilation of knowledge on civic consciousness as a social phenomenon that provides a meaningful approach to this concept in the process of studying of humanities and social sciences at universities;

- Contributes to the knowledge of the history and culture of the fatherland, its traditions, giving the necessary understanding of their country, civil society, rights and obligations that determine the ways of interaction in civil society.

Secondly, the axiological component is aimed at developing of values of civil society (rights and freedoms, tolerance, humanism and democracy, etc.) at young people in universities. It ensures the assimilation of social behavior norms, civic attitude, and awareness of their personal significance, which is ultimately expressed in the value attitude to the future profession. Learning is a good illustration of how these ways are working.

This component is aimed at value understanding of events and phenomena occurring in society, determining life - meaningful guidelines and worldview attitudes, gaining the ability to interpret complex social problems and, in this regard, to form value-significant personal qualities.

Third, the motivational component expresses the attitude of a young person to entering in civil society on the basis of inner stable motivation that determine his/her life strategies as a future specialist, the desire for civic responsibility, active social behavior, and encouraging legitimate responsible actions. It is impossible without internal motivation for civil behavior and perception of civil values, socially significant attitude to the laws, and recognition of rights and freedoms of citizens. It leads to self-report, self-development, rethinking of students ' attitude to reality, social roles, norms, ideals, and rules (see S.V.Gladchenkova 2008 ).

Fourth, the activity component determines the real behavior of young persons in civil society, their ability to observe moral and legal norms, carry out social and moral duties in accordance with their civil attitude, form relationship between a citizen, society, and state. We consider that the educational environment is a space for civil development and presentation of skills, experience, and readiness for future professional activities (L. Farafonova 2006).

\section{PERSONALITY AND CIVIC CONSCIOUSNESS}

The concept of personality includes social and spiritual components. The question of spiritual activity can be analyzed on a new and more fundamental level. It supposes the unity of the citizen and the integral personality, rights and responsibilities. Civic consciousness is the basis of human intercourse of given 
culture, society, and the state. Of course, some profound changes in culture take place. They are shaped primarily by technological capabilities, cyberspace, for example. But the core of culture preserves language, symbols, and spiritual values. They allow us to create meaning and abstract ideas to perform the function of integration. Being recorded, they can be transmitted for succeeding generations.

The organization of activities for the education of civic consciousness is aimed at the formation of a fully developed personality of a student. The formation of high professional and moral qualities at studenthonesty, attentive attitude to people, universal and legal culture-ensures the professional and moral qualities of students, their resistance to the impact of deviant behavior. The moral values acquired during the educational process (especially in studying of humanities and social sciences), form the foundation of student's moral component which embodies the awareness of involvement in the national history, culture, heroic past of the country, victories, achievements, and successes of previous generations. Patriotic values are the spiritual bonds of a society.

Education of civic consciousness in educational organizations is a process aimed at the formation of socially significant personal qualities at students; development of high professional qualities, creating conditions for self-realization of personality. Besides, the educational process is aimed at acquiring of ideal - moral beliefs, moral qualities and feelings, stable and habitual norms of behavior, corresponding to a clear civil attitude. The core of civil attitude is the transition of moral principles into the internal attitudes and personal beliefs of each individual. The role of a teacher in this activity is invaluable. It is the teacher who transmits to student knowledge about the norms, principles, ideals and signs of moral behavior; influences on a personality, setting a positive example; creates an atmosphere of approval of high-moral behavior and a clear civil attitude in educational team.

The process of education of civic consciousness is a complex one. On the one hand, it involves the formation of a person's necessary ideas about the civil attitude, its true content, and other moral principles and norms. On the other hand, the education of civic consciousness consists in creating a deep inner need at students to act in accordance with the civil obligation.

We point out the duality of the concept of civic consciousness. Similarly, V.I. Dahl defined civic consciousness as a dyadic conception. He noted that the concept of civil related not only to citizens, the state, and people's governing, but included relationships to the others, the relation between "me" and thee". Dahl defines civic consciousness as follows:" civic consciousness is a state of a civil community, ideas and the degree of formation which are necessary for the organization of a civil society." (Dahl 1978, 137).

Consequently, the concept of civic consciousness correlates not only with the legal status of a person, but also with the degree of education, being formed understanding of a state of society, as well as with social normativity and socially accepted norms of morality. In this aspect, civic consciousness is considered as a generalized expression of moral norms, giving a social orientation to human behavior in the sphere of moral relations and being a guideline in social activity. Civic consciousness as a social and moral phenomenon reflects the most essential requirements, putting forward by society, the state, and the collectivity to an individual and its life activity. A teacher should constantly explain that there is a civil duty, so that it becomes a self- conscious internal motivation of a personality. The humanities and social sciences serve this purpose primarily.

\section{CONCLUSION}

The concept of civic consciousness has a long history. We tried to broaden the theoretical framework for analyzing civic consciousness so that it might encompass both as a unity of cognitive, motivational, axiological, and activity components and understanding this concept from a worldview perspective as a personal phenomenon that needs to be formed in the educational process at universities. The definition of civic consciousness has basis in the spiritual and social world. The modern civilization is characterized by the processes of globalization. Human beings share a common fate. We can point out a deep acute macro social contradiction: the universal cultural trait of globalization which erases cultural differences and particularism of national cultures, natural bases of people's lives. Culture always has national character and roots. So it is important to love his/her country and his/her own people. The formation of civic consciousness provides the real basis for the idea of special mission of understanding and preserving of uniqueness of culture, patriotic and national feelings which give rise to inspiration and transmission of cultural values and traditions of the past to the next generation. The production of civic consciousness allows emphasizing individual socially significant motivation and attitudes, civic values and beliefs, knowledge in the field of rights, freedoms and obligations of a citizen, civil behavior skills, professionally significant qualities that are expressed in patriotism and statehood. 
But it is not always possible due to the objective and subjective reasons, unfortunately.

\section{REFERENCE LIST}

1. Almond, Gabriel A, Verba, Sidney, 1963. The Civic Culture. Political Attitudes and Democracy in Five Countries, Princenton.

2. Aronov, A. A., 1989. To Educate Patriots, Moscow: Prosveshchenie.

3. Aristotle, 1984. Works in 4 volumes, vol. 4, Moscow: Mysl.

4. Belozertsev ,E. P., 2000. Image and Meaning of the Russian School: Essays on Applied Philosophy of Education, Volgograd: Peremena.

5. Bradley, Joseph, 2009. Voluntary Associations in Tsarist Russia, London, Harvard University Press.

6. Bueva, L. P., 1971. Sociology and Pedagogy, Moscow: Academy of Pedagogical Sciences.

7. Dahl, V.I., 1978. Explanatory Dictionary of the Living Great Russian Language, SPb.: ID All.

8. Danilov, M. A., 2005. Didactics, Moscow: Nauka.

9. Farafonova L., 2006. Some Aspects of Civil Education of Youth, Journal of Higher Education in Russia, 12: 71-74.

10.Fourier, Charles, 1939. On Education at the Harmonious Society, Moscow: Uchpedgiz.

11.Gladchenkova, S. V., 2008. Formation of Civil Attitude of Lawyers in the Process of Education at University, Bryansk: University of Bryansk Press.

12.Kagan, M. S., 1974. Human Activities, Moscow: Nauka.

13.Makarenko, A.S., 1986. Pedagogical Works in 8 Volumes, Moscow: Pedagogika.

14. Montaigne, Michel, 2019. Experiments, Moscow: AST.

15.Plato, 2017. Complete Works in One Volume, Moscow: Alpha-Kniga.

16. Rotterdamus, Erasmus, 1986. Philosophical Works, Moscow: Nauka.

17.Rousseau,_Jean-Jacques, 1981. Pedagogical Works in 2 Volumes, Moscow: Pedagogika.

18.Saint-Simon, Claude, Henri, 1948. Selected Works in 2 Volumes, Moscow: Publishing House of the Academy of Sciences.

19.Shatalovich, O. I., 2006. Cultural Basis of the Process of Forming of Civil Attitude of Schoolchildren , Journal of Humanities and Socio-economic Sciences. Special Issue. Pedagogy, 5: 106-111.

20.Sukhomlinsky, V. A. Birth of a Citizen https://insportal.ru/node/21540/2011/10/sukhomlinsky ...

21. Ushinsky K. S., 2004. Man as a Subject of Education: Experience of Pedagogical Anthropology, Moscow: Fair Press. 